\title{
The impact of news on measures of undiversifiable risk: evidence from the UK stock market
}

Article

Accepted Version

Brooks, C. and Henry, O.T. (2002) The impact of news on measures of undiversifiable risk: evidence from the UK stock market. Oxford Bulletin of Economics and Statistics, 64 (5). pp. 487-507. ISSN 1468-0084 doi: https://doi.org/10.1111/14680084.00274 Available at https://centaur.reading.ac.uk/24149/

It is advisable to refer to the publisher's version if you intend to cite from the work. See Guidance on citing.

To link to this article DOI: http://dx.doi.org/10.1111/1468-0084.00274

Publisher: Blackwell Publishing Ltd

All outputs in CentAUR are protected by Intellectual Property Rights law, including copyright law. Copyright and IPR is retained by the creators or other copyright holders. Terms and conditions for use of this material are defined in the End User Agreement.

$\underline{\text { www.reading.ac.uk/centaur }}$ 
Central Archive at the University of Reading

Reading's research outputs online 
This is the authors' accepted manuscript of an article published in the Oxford Bulletin of Economics and Statistics. The definitive version is available at www3.interscience.wiley.com 


\title{
The Impact of News on Measures of Undiversifiable Risk: Evidence from the UK Stock Market ${ }^{*}$
}

\author{
Chris Brooks (corresponding author) \\ ISMA Centre, The University of Reading, \\ Whiteknights Park, PO Box 242, Reading RG6 6BA \\ United Kingdom. \\ Tel: +44 (0)1189316768 \\ Fax: +44 (0)1189314741 \\ E-Mail: c.brooks@ismacentre.rdg.ac.uk \\ Ólan T. Henry, \\ Department of Economics, University of Melbourne \\ Victoria 3010 Australia \\ Tel: + 613383445312 \\ Fax: +613383446899 \\ E-mail: oth@unimelb.edu.au \\ http://melbecon.unimelb.edu.au/staffprofile/ohenry/home.html
}

This Version: May 2002

\begin{abstract}
Using UK equity index data, this paper considers the impact of news on time varying measures of beta, the usual measure of undiversifiable risk. The empirical model implies that beta depends on news about the market and news about the sector. The asymmetric response of beta to news about the market is consistent across all sectors considered. Recent research is divided as to whether abnormalities in equity returns arise from changes in expected returns in an efficient market or over-reactions to new information. The evidence suggests that such abnormalities may be due to changes in expected returns caused by time-variation and asymmetry in beta.
\end{abstract}

JEL Codes: G12 G15

Keywords: Stock Index, Multivariate Asymmetric GARCH, News Impact Surfaces, Conditional Beta Surfaces.

\footnotetext{
Initial work on this paper took place while the second author was on study leave at the ISMA Centre, The University of Reading. The News impact surfaces were graphed using a GAUSS Routine written by the second author and Michalis Ioannides. The data and estimation routines are available upon request from the corresponding author. We are indebted to Kalvinder Shields, seminar participants at the University of Manchester and RMIT University and to an anonymous referee for helpful comments on earlier drafts of this paper. The responsibility for any errors or omissions lies solely with the authors.
} 


\section{Introduction}

There is widespread evidence that the volatility of equity returns is higher in bull markets than in bear markets. One potential explanation for such asymmetry in variance is the so-called 'leverage effect' of Black (1976) and Christie (1982). As equity values fall, the weight attached to debt in a firm's capital structure rises, ceteris paribus. This induces equity holders, who bear the residual risk of the firm, to perceive the stream of future income accruing to their portfolios as being relatively more risky.

An alternative view is provided by the 'volatility-feedback' hypothesis. Assuming constant dividends, if expected returns increase when stock return volatility increases, then stock prices should fall when volatility rises. Pagan and Schwert (1990), Nelson (1991), Campbell and Hentschel (1992), Engle and Ng (1993), Glosten, Jagannathan and Runkle (1993), and Henry (1998), inter alia, provide evidence of asymmetry in equity return volatility using univariate GARCH models. Kroner and Ng (1995), Braun, Nelson and Sunnier (1995), Henry and Sharma (1999), Engle and Cho (1999), and Brooks and Henry (2000) inter alia use multivariate GARCH models to capture time-variation and asymmetry in the variance-covariance structure of asset returns.

Such time-variation and asymmetry in volatility may be used to explain a timevarying and asymmetric beta. A risk averse investor will trade off higher levels of expected return for higher levels of risk. If the risk premium is increasing in volatility, and if beta is an adequate measure of the sensitivity to risk, then time-variation and asymmetry in the variance-covariance structure of returns may lead to time-variation and asymmetry in beta.

Recent research by Braun, Nelson and Sunnier (1995), hereafter BNS, explores time variation and asymmetry in beta using a bivariate EGARCH model. Engle and Cho (1999), hereafter EC, extend the BNS paper in two main directions. First, EC consider the differing roles of market- and asset-specific shocks. This is important since a series of negative returns caused by market or asset-specific shocks may lead to an increase in beta. Second, EC use daily data on individual firms, rather than the aggregated data used by BNS. 
Our approach differs from that of both BNS and EC. In particular we use a linear as opposed to an exponential multivariate GARCH model to distinguish between the roles of idiosyncratic and market shocks in determining potential asymmetry in beta. The exponential GARCH approach of BNS does not readily admit negative covariance estimates although such inverse relationships may be present in the data. Moreover, the EGARCH form appears to overstate the response of the conditional variance to a negative shock - see Engle and $\mathrm{Ng}$ (1993), and Henry (1998), inter alia. Our approach allows for a (potentially negative) time varying and asymmetric covariance between the risky asset and market portfolio, while guaranteeing a positive definite variance-covariance matrix. Moreover, we define the Conditional Beta Surface, an extension of the News Impact Surface concept of $\mathrm{Ng}$ and Kroner (1995). Using this approach it is possible to produce a graphical representation of the impact of idiosyncratic and market-wide shocks upon estimates of beta. We also employ indicator dummy regressions to identify sources of the observed asymmetry in the estimated beta series. The models are applied in the context of the estimation of beta for six UK sector return indices.

The remainder of the paper develops as follows. Section 2 outlines the strategy employed for modelling the time-variation and asymmetry in beta, while section 3 describes the data and presents the empirical results. The statistical properties of the estimated beta series are reported in section 4 . The final section of the paper provides a summary and some concluding comments.

\section{Modelling Time Variation and Asymmetry in Beta}

The static Capital Asset Pricing Model (CAPM) predicts that the expected return to investing in a risky asset or portfolio, $\mathrm{E}\left(R_{S, t}\right)$, should equal, $r_{f}$, the risk free rate of return, plus a risk premium. The risk premium is determined by a price of risk, the expected return 
on the market portfolio in excess of $r_{f}$, and a quantity of risk, known as the 'beta' of asset $S$, $\beta_{S}$. The static CAPM may be written as

$$
E\left(R_{S}\right)=r_{f}+\left[E\left(R_{M}\right)-r_{f}\right] \beta_{S}
$$

where $M$ and $S$ denote the market and sector respectively, $\beta_{S}=\frac{\operatorname{Cov}\left(R_{M}, R_{S}\right)}{\operatorname{Var}\left(R_{M}\right)}$, and $\operatorname{Cov}\left(R_{M}, R_{S}\right)$ and $\operatorname{Var}\left(R_{M}\right)$ are the covariance between the sector and market portfolio returns and the variance of the market returns, respectively ${ }^{1}$.

Estimates of $\beta_{S}$ may be obtained from OLS estimates of the slope coefficient in

$$
R_{S, t}=b_{0}+b_{1} R_{M, t}+u_{t}
$$

It has long been recognised that the volatility of asset returns is clustered. Thus the assumption of constant variance (let alone covariance) underlying the estimation of (2) must be regarded as tenuous.

Let $E_{t-1}($.$) represent the expectations operator conditional on information available at$ time $t$-1. The conditional formulation of the Capital Asset Pricing Model (CAPM) predicts that the expected return to investing in a risky asset or portfolio, $E_{t-1}\left(R_{S, t}\right)$, should equal the risk free rate of return plus a risk premium. The risk premium is determined by a price of risk, $E_{t-1}\left(R_{M, t}\right)-r_{f}$, and a quantity of risk, the beta of asset $S, \beta_{S, t}$. This may be written as

$$
E_{t-1}\left(R_{S, t}\right)=r_{f}+\left[E_{t-1}\left(R_{M, t}\right)-r_{f}\right] \frac{\operatorname{cov}_{t}\left(R_{S, t}, R_{M, t}\right)}{\operatorname{var}_{t}\left(R_{M, t}\right)}
$$

where $\beta_{S, t}=\operatorname{cov}_{t}\left(R_{S, t} R_{M, t}\right) / \operatorname{var}_{t}\left(R_{M, t}\right)$, and $\operatorname{cov}_{t}\left(R_{S, t} R_{M, t}\right)$ and $\operatorname{var}_{t}\left(R_{M, t}\right)$ are the conditional covariance between the asset and market portfolio returns and the conditional variance of the market returns respectively. Note that (3) assumes investors maximise utility period by period and is written in terms of the conditional moments, reflecting market

\footnotetext{
${ }^{1}$ The CAPM can be written as $E\left(R_{i}\right)=r_{f}+\rho \operatorname{COV}\left(R_{S}, R_{M}\right)$, where $\rho$ is the market price per unit risk.
} 
participants' use of information available up to time $t-1$ in making investment decisions for time $t$. Unlike the static CAPM, (3) does not require constant $\beta_{S}$ or constant risk premia.

The model presented by Merton $(1973,1980)$ predicts a positive relationship between the market risk premium and the variance of the market portfolio. Bollerslev, Engle and Wooldridge (1988), Braun, Nelson and Sunier (1995) and Engle and Cho (1999), inter alia, report evidence of time variation in $\beta_{S, t}$ based upon the GARCH class of models. Attanasio (1991), Engel, Frankel, Froot and Rodrigues (1995) and González-Rivera (1996) present tests of the conditional CAPM allowing for predictability of the second moment of asset returns. González-Rivera (1996) presents a testable version of the conditional CAPM written as

$$
E_{t-1}\left(R_{S, t}\right)=r_{f}+\delta \operatorname{cov}_{t}\left(R_{S, t}, R_{M, t}\right)
$$

where $\delta=\left[E\left(R_{M, t}\right)-r_{f}\right] / \operatorname{var}_{t}\left(R_{M, t}\right)$ represents the aggregate coefficient of relative risk aversion and is assumed constant over time.

The focus of this paper is on the time series behaviour of $\beta_{S, t}$ and in particular whether there is evidence of asymmetry in this measure of risk. Braun, Nelson and Sunnier (1995) and Engle and Cho (1999) use the bivariate EGARCH approach specifying the conditional mean equations as

$$
\begin{aligned}
& \tilde{R}_{M, t}=h_{M, t} z_{M, t} \\
& \tilde{R}_{S, t}=\beta_{S, t} R_{M, t}+h_{S, t} z_{S, t}
\end{aligned}
$$

where $\tilde{R}_{M, t}$ and $\tilde{R}_{S, t}$ represent the demeaned returns to the market and sector respectively, $z_{M, t}$ and $z_{S, t}$ are contemporaneously uncorrelated i.i.d. processes with zero mean and unit variance and $h_{M, t}$ and $h_{S, t}$ are the conditional variances of $\tilde{R}_{M, t}$ and $\tilde{R}_{S, t}$, respectively. The measure of undiversifiable risk associated with industry sector $S, \beta_{S}$, is defined as:

$$
\beta_{S, t}=\frac{E_{t-1}\left[\tilde{R}_{M, t} \cdot \tilde{R}_{S, t}\right]}{E_{t-1}\left[\tilde{R}_{M, t}^{2}\right]}
$$


where $E_{t-1}[$.$] denotes the expectation at time t-1$. The model is completed by the equations defining the time series behaviour of $h_{M, t}, h_{S, t}$ and $\beta_{S, t}$

$\ln \left(h_{M, t}\right)=\varpi_{M}+\phi_{M}\left\lfloor\ln \left(h_{M, t-1}\right)-\varpi_{M}\right\rfloor+\gamma_{M} z_{M, t-1}+\lambda_{M} g_{m}\left(z_{M, t-1}\right)$

$\ln \left(h_{S, t}\right)=\varpi_{S}+\phi_{S}\left[\ln \left(h_{S, t-1}\right)-\varpi_{S}\right]+\gamma_{S} z_{S, t-1}+\lambda_{S} g_{S}\left(z_{S, t-1}\right)+\lambda_{S, M} g_{m}\left(z_{M, t-1}\right)$

$\beta_{S, t}=\xi_{0}+\xi_{4}\left[\beta_{S, t-1}-\xi_{0}\right]+\xi_{1} z_{M, t-1} z_{S, t-1}+\xi_{2} z_{M, t-1}+\xi_{3} z_{S, t-1}$

where $g_{i}\left(z_{i, t-1}\right)=\left[z_{i, t-1}|-E| z_{i, t-1} \mid\right]$ for $i=M, S$.

As noted by Braun et al. (1995), the bivariate EGARCH (7) implies some strong assumptions. First, the model does not allow for feedback, as would be the case if $\ln \left(h_{M, t}\right), \ln \left(h_{S, t}\right)$ and $\beta_{S, t}$ followed a VARMA process. Second, the model assumes a linear autoregressive process for $\beta_{S, t}$. Third, although the model allows for leverage effects, it does so in an ad-hoc fashion.

In contrast to Braun, Nelson and Sunnier (1995), and Engle and Cho (1999), our approach allows for feedback between the conditional means and variances of $R_{M, t}$ and $R_{S, t}$. Furthermore, we make no formal assumptions as to the time series process underlying $\beta_{S, t}$. We assume a VARMA process for the returns and model the time variation in the variance-covariance matrix using a linear as opposed to an exponential GARCH model. The multivariate GARCH approach allows the researcher to examine the effects of shocks to the entire variance-covariance matrix. Thus the effect of a shock to $R_{M, t}$ on the covariance between $R_{M, t}$ and $R_{S, t}$ may be inferred directly from the parameter estimates. Moreover, the conditional variance-covariance matrix may be parameterised to be time varying and asymmetric. Given the role of covariances in asset pricing and financial risk management, correct specification of the variance-covariance structure is of paramount importance. For example, the conditional covariance may be used in the calculation of prices for options involving more than one underlying asset (such as rainbow options), and is vital to the 
calculation of minimum capital risk requirements, see Brooks, Henry and Persand (2002). Both variance and covariance estimates may be used in the calculation of the measure of undiversifiable risk from the Capital Asset Pricing Model. It follows that if the variance and/or covariance terms are time-varying (and asymmetric), the CAPM $\beta$ is also likely to be time-varying (and asymmetric).

The conditional mean equations of the model are specified in our study as a Vector Autoregressive Moving Average (VARMA) with conditional variance and covariance terms, which may be written as:

$$
\begin{aligned}
& Y_{t}=\mu+\sum_{j=1}^{m} \Gamma_{j} Y_{t-j}+\sum_{k=1}^{n} \Theta_{k} \varepsilon_{t-k}+\Psi \operatorname{vech}\left(H_{t}\right)+\varepsilon_{t} \\
& Y_{t}=\left[\begin{array}{c}
R_{M, t} \\
R_{S, t}
\end{array}\right] ; \mu=\left[\begin{array}{c}
\mu_{M} \\
\mu_{S}
\end{array}\right] ; \Gamma_{j}=\left[\begin{array}{cc}
\Gamma_{j, M}^{(M)} & \Gamma_{j, S}^{(M)} \\
\Gamma_{j, M}^{(S)} & \Gamma_{j, S}^{(S)}
\end{array}\right] ; \\
& \Theta_{k}=\left[\begin{array}{ll}
\Theta_{k, M}^{(M)} & \Theta_{k, S}^{(M)} \\
\Theta_{k, M}^{(S)} & \Theta_{k, S}^{(S)}
\end{array}\right] ; \Psi=\left[\begin{array}{c}
\psi_{1, S} \psi_{1, S M} \psi_{1, M} \\
\psi_{2, S} \psi_{2, S M} \psi_{2, M}
\end{array}\right] ; \varepsilon_{t}=\left[\begin{array}{c}
\varepsilon_{M, t} \\
\varepsilon_{S, t}
\end{array}\right]
\end{aligned}
$$

where vech is the column stacking operator of a lower triangular matrix.

$$
\text { If } \varepsilon_{t} \mid \Omega_{t-1} \sim\left(0, H_{t}\right) \text {, where } H_{t}=\left[\begin{array}{cc}
H_{M, t} & H_{M S, t} \\
H_{M S, t} & H_{S, t}
\end{array}\right] \text { and } \varepsilon_{t} \text { represents the innovation }
$$

vector in (8), the bivariate $\operatorname{VARMA}(m, n) \operatorname{GARCH}(1,1)$ model may be written as (9), the BEKK parameterisation proposed by Engle and Kroner (1995)

$$
H_{t}=C_{0}^{* \prime} C_{0}^{*}+A_{11}^{* \prime} H_{t-1} A_{11}^{*}+B_{11}^{* \prime} \varepsilon_{t-1} \varepsilon_{t-1}^{\prime} B_{11}^{*}
$$

The BEKK parameterisation requires estimation of only 11 parameters in the conditional variance-covariance structure and guarantees $H_{t}$ positive definite. It is important to note that the BEKK model implies that only the magnitude of past return innovations is important in determining current conditional variances and covariances. This assumption of symmetric time-varying variance-covariance matrices must be considered tenuous given the existing body of evidence documenting the asymmetric response of equity volatility to positive and negative innovations of equal magnitude (see Engle and $\mathrm{Ng}$, 1993, Glosten, Jagannathan and Runkle, 1993, Kroner and Ng, 1996, and Brooks, Henry and Persand, 2002, inter alia). 
Defining $\xi_{i, t}=\min \left\{\varepsilon_{i, t}, 0\right\}$ for $i=M, S$, the BEKK model in (9) may be extended to allow for asymmetric responses as

$$
H_{t}=C_{0}^{* \prime} C_{0}^{*}+A_{11}^{* \prime} H_{t-1} A_{11}^{*}+B_{11}^{* \prime} \varepsilon_{t-1} \varepsilon_{t-1}^{\prime} B_{11}^{*}+D_{11}^{* \prime} \xi_{t-1} \xi_{t-1}^{\prime} D_{11}^{*}
$$

with the following definitions of the coefficient matrices:

$$
\begin{aligned}
& C_{0}^{*}=\left[\begin{array}{cc}
c_{11}^{*} & c_{12}^{*} \\
0 & c_{22}^{*}
\end{array}\right] ; \quad A_{11}^{*}=\left[\begin{array}{cc}
a_{11}^{*} & a_{12}^{*} \\
a_{21}^{*} & a_{22}^{*}
\end{array}\right] ; \\
& B_{11}^{*}=\left[\begin{array}{ll}
b_{11}^{*} & b_{12}^{*} \\
b_{21}^{*} & b_{22}^{*}
\end{array}\right] ; \quad D_{11}^{*}=\left[\begin{array}{ll}
d_{11}^{*} & d_{12}^{*} \\
d_{21}^{*} & d_{22}^{*}
\end{array}\right] \quad \text { and } \quad \xi_{t}=\left[\begin{array}{c}
\xi_{M, t} \\
\xi_{S, t}
\end{array}\right]
\end{aligned}
$$

The symmetric $B E K K$ model (9) is given as a special case of (10) where all the elements of $D_{11}^{*}$ equal zero. Given estimates of $H_{M S, t}$, the conditional covariance between the return to the market portfolio, $R_{M, t}$, and the return to the individual sector, $R_{S, t}$, and the variance of return to the market portfolio, $H_{M, t}$, it is possible to calculate a time varying estimate of $\beta_{S}$, the measure of undiversifiable risk associated with industry sector $S$ as:

$$
\beta_{S, t}=\frac{H_{M S, t}}{H_{M, t}} .
$$

Previous studies by Ballie and Myers (1991), Kroner and Sultan (1991), and Brooks, Henry and Persand (2002) have considered the time series properties of $\beta_{S, t}$ constructed in this fashion in the context of dynamic hedging using futures contracts. Attanasio (1991), Engel et al (1995), and González-Rivera (1996), inter alia, test the CAPM but do not discuss the time series properties of the estimated $\beta_{S, t}$ series.

Kroner and Ng (1996) analyse the asymmetric properties of time-varying covariance matrix models, identifying three possible forms of asymmetric behaviour. First, the covariance matrix displays own variance asymmetry if $h_{M, t}\left(h_{S, t}\right)$, the conditional variance of $R_{M, t}\left(R_{S, t}\right)$, is affected by the sign of the innovation in $R_{M, t}\left(R_{S, t}\right)$. Second, the covariance matrix displays cross variance asymmetry if the conditional variance of 
$R_{M, t}\left(R_{S, t}\right)$ is affected by the sign of the innovation in $R_{S, t}\left(R_{M, t}\right)$. Finally, if the covariance of returns $H_{M S, t}$ is sensitive to the sign of the innovation in return for either portfolio, the model is said to display covariance asymmetry.

The innovation in the $\log$ of the prices from time $t-1$ to time $t$, denoted, $\log \left(P_{i, t}\right)-\log \left(P_{i, t-1}\right)=\varepsilon_{i, t}, i=M, S$, represents changes in information available to the market (ceteris paribus). Kroner and $\mathrm{Ng}$ (1996) treat such innovations as collective measures of news arriving to market $i$ between the close of trade on period $t-1$ and the close of trade on period $t$. Kroner and $\mathrm{Ng}$ (1996) define the relationship between innovations in returns and the conditional variance-covariance structure as the news impact surface, a multivariate form of the news impact curve of Engle and $\mathrm{Ng}$ (1993).

\section{Data Descriptions and Empirical Results}

Weekly UK equity index data for the period $01 / 01 / 1965$ to $01 / 12 / 1999$ was obtained from Datastream International. The FT-All Shares index was used as a proxy for the market portfolio. The paper reports results for six sector return indices, namely Basic Industries (BASICUK), Total Financials (TOTLFUK), Healthcare, (HLTHCUK), Publishing (PUBLSUK), Retail (RTAILUK) and Real Estate, (RLESTUK) ${ }^{2}$. In all cases the data were in accumulation index form and were transformed into continuously compounded returns for each sector in the standard fashion. Summary statistics for the data are presented in Table 1. As one might anticipate, the data display evidence of extreme non-normality. In only one case, Healthcare, is the degree of skewness not statistically significant. In all cases, the data display strong evidence of excess kurtosis. Columns 1 and 2 of Figure 1 display the index and returns data respectively. Visual inspection of the graph of the returns data suggests that there is strong volatility clustering. A Ljung-Box test on the squared return data suggests that there

\footnotetext{
${ }^{2}$ The results for the remaining sectors are qualitatively unchanged from those reported here, and are available on request from the authors.
} 
is strong evidence of Autoregressive Conditional Heteroscedasticity $(\mathrm{ARCH})$ in the data. The final column of Table 1 displays static estimates of undiversifiable risk obtained from OLS estimation of (2). The range of estimates runs from 0.930 for Health Care to 1.079 for Retailing.

The Akaike and Schwarz information criteria were used to determine the lag order of the VARMA model (8). In all cases, the restricted $\operatorname{VARMA}(2,1)$ given as $(13)$ was deemed optimal:

$$
\begin{aligned}
Y_{t} & =\mu+\sum_{j=1}^{2} \Gamma_{j} Y_{t-j}+\Theta_{1} \varepsilon_{t-1}+\Psi \operatorname{vech}\left(H_{t}\right)+\varepsilon_{t} \\
Y_{t} & =\left[\begin{array}{c}
R_{M, t} \\
R_{S, t}
\end{array}\right] ; \mu=\left[\begin{array}{c}
\mu_{M} \\
\mu_{S}
\end{array}\right] ; \Gamma_{j}=\left[\begin{array}{cc}
\Gamma_{j, M}^{(M)} & \Gamma_{j, S}^{(M)} \\
\Gamma_{j, M}^{(S)} & \Gamma_{j, S}^{(S)}
\end{array}\right] ; \\
\Theta_{1} & =\left[\begin{array}{cc}
\Theta_{1, M}^{(M)} & 0 \\
0 & \Theta_{1, S}^{(S)}
\end{array}\right] ; \Psi=\left[\begin{array}{l}
\psi_{1, S} \psi_{1, S M} \psi_{1, M} \\
\psi_{2, S} \psi_{2, S M} \psi_{2, M}
\end{array}\right] ; \varepsilon_{t}=\left[\begin{array}{c}
\varepsilon_{M, t} \\
\varepsilon_{S, t}
\end{array}\right]
\end{aligned}
$$

Maximum likelihood techniques were used to obtain estimates of parameters for equations (10) and (13) assuming Student's- $t$ distributions with unknown degrees of freedom for the errors. The parameter estimates for the conditional mean and variance equations are displayed in Tables $2 \mathrm{a}, 2 \mathrm{~b}$ and the upper panel of Table $2 \mathrm{c}$.

Shocks to volatility appear highly persistent. Estimates of the main diagonal elements of $A_{11}^{*}$ are, in general, close to unity. There is strong evidence of own variance, cross variance and covariance asymmetry in the data. This is highlighted by the significance of the parameters in the $D_{11}^{*}$ matrix. The insignificance of the off-diagonal elements in the $B_{11}^{*}$ matrix suggests that the majority of important volatility spillovers from the market to the sector are associated with negative realisations of $R_{M, t}$. Taken together, the evidence suggests that news about the individual portfolios (market or sector) impacts only upon that individual portfolio volatility. However, bad news about the market portfolio spills over into the individual sector portfolios without evidence of feedback from sector to market. 
The upper panel of Table $2 \mathrm{c}$ displays the estimates of the $\Psi$ matrix. The conditional CAPM suggests a positive relationship between the market risk premium and the variance of the market portfolio. This condition is not supported by the data for the Basic Industries and Total Financials Sectors with $\hat{\psi}_{1, M}<0$ and significant. Similarly for Total Financials, Retail and Real Estate $\hat{\psi}_{1, S M}<0$ and significant. As $\hat{\psi}_{1, S M}$ can be interpreted as an estimate of the coefficient of risk aversion these estimates are not consistent with existing estimates in the literature, see Hansen and Singleton (1983) inter alia. While the focus of this paper is not on testing the conditional CAPM, these results are suggestive of the theory being incompatible with the data.

With the exception of the health sector, the models all pass the usual Ljung-Box test for serial correlation in the standardised and squared standardised residuals displayed in Table 2c.

Figures 2-7 display the variance and covariance news impact surfaces for the estimates of the Multivariate GARCH model displayed in Table 2. Following Engle and $\mathrm{Ng}$ (1993) and $\mathrm{Ng}$ and Kroner (1996), each surface is evaluated in the region $\varepsilon_{i, t}=[-5,5]$ for $i$ $=M, S$, holding information at time $t-1$ and before constant. There are relatively few extreme outliers in the data, which suggests that some caution should be exercised in interpreting the news impact surfaces for large absolute values of $\varepsilon_{i, t}$. Despite this caveat, the asymmetry in variance and covariance is clear from each Figure. The sign and magnitude of idiosyncratic and market shocks have clearly differing impacts on elements of $H_{t}$. The first panel of each Figure shows the effect of idiosyncratic and market-wide shocks on subsequent market volatility. It is evident that for the basic industries, healthcare and publishing sectors, positive idiosyncratic shocks have virtually no effect on next period market volatility, while negative shocks have moderate impacts. On the other hand, in the cases of the financial and real estate sectors, idiosyncratic shocks have a much stronger role to play. In the cases of the basic industries, retail and healthcare sectors, a market-wide shock has a bigger impact on 
subsequent sector volatility than an idiosyncratic shock of the same size. The third panels of Figures 2 to 7 show the effects of idiosyncratic and market-wide shocks on future conditional covariance between market and sector returns. For the basic industries, financial, healthcare and retail sectors, it appears to be the sector-specific shocks that drive the covariances, with negative shocks having considerably larger effects than positive shocks of the same magnitude.

Holding information at time $t-1$ and before constant, and evaluating $\beta_{S, t}$ as before yields the response of the measure of undiversifiable risk to news. The fourth panels of Figures 2-7 graph the response of $\beta_{S, t}$ to news using the estimates displayed in Table 2. Again, the asymmetry in response to market and idiosyncratic shocks is clear. For example, visual inspection of the fourth panel of Figure 2 suggests the differing response of $\beta_{S, t}$ to idiosyncratic and market-wide shocks. The basic industries beta appears to respond largely to idiosyncratic shocks. On the other hand, Figure 3 suggests that the total financials beta responds far more to market-wide shocks. In the course of daily business, providing liquidity and capital, the financial sector becomes exposed to risk across all sectors of the economy; thus it is intuitively appealing that the beta for the financial sector appears to respond strongly to news about the market. Such visual analysis, while intuitively appealing, is obviously ad-hoc and subjective, therefore the paper now moves to a more formal statistical analysis of the sources of the observed asymmetry.

\section{Properties of the $\hat{\beta}_{S, t}$ series}

By construction, the model allows $\beta_{S}$, the measure of undiversifiable risk associated with industry sector $S$ to respond asymmetrically to news about the market portfolio and/or news about sector $S$. Brooks, Henry and Persand (2002) argue that the dependence of beta on news is important in the context of dynamic hedging, particularly in the presence of asymmetries. The third column of Figure 1 plots the estimated $\hat{\beta}_{S, t}$. The time variation of the 
measure of undiversifiable risk across each sector is evident. Table 3 presents descriptive statistics for the $\hat{\beta}_{S, t}$ series. The most volatile of the $\hat{\beta}_{S, t}$ series is associated with the real estate sector. Here the $\hat{\beta}_{S, t}$ ranges from a minimum of 0.44 to a maximum of 1.48 . In terms of the average value of $\hat{\beta}_{S, t}$, retailing appears to be the riskiest sector, with a $\hat{\beta}_{S, t}=1.11$, indicating that retailing has higher risk than the market portfolio which has $\beta_{M, t}=1 \forall t$ by definition. The averages of the $\hat{\beta}_{S, t}$ series compare closely with the static estimates presented in Table 1. On the basis of a sequence of augmented Dickey-Fuller unit root tests, the $\hat{\beta}_{S, t}$ series appear stationary.

What factors underlay the observed asymmetry in $\hat{\beta}_{S, t}$ ? EC argue that shocks to the market and idiosyncratic shocks determine asymmetric effects in $\hat{\beta}_{S, t}$. This logic underlies the News Impact Surface that we propose for $\hat{\beta}_{S, t}$ depicted in Figures 2 to 6 . To identify negative returns to the market, let $I_{M, t}$ represent an indicator variable, which takes the value of unity when $R_{M, t}$, the return to the market portfolio, is negative and zero otherwise. Similarly, in order to identify the magnitude of negative market returns, let $R_{M, t}^{-}=I_{M, t} \times R_{M, t}$. Similar variables may be defined to identify negative return innovations and the corresponding magnitudes for each individual sector.

Consider the OLS regression

$$
\hat{\beta}_{S, t}=\phi_{1}+\phi_{2} I_{M, t}+\phi_{3} R_{M, t}^{-}+\phi_{4} I_{S, t}+\phi_{5} R_{S, t}^{-}+\phi_{6} C_{S, t}+\phi_{7} C_{M, t}+u_{t}
$$

where $C_{S, t}=I_{M, t} \times R_{S, t}$, and $C_{M, t}=I_{S, t} \times R_{M, t}$ represent dummy variables designed to capture the sector return when the market return is negative $\left(C_{S, t}\right)$ and the market return when the sector return is negative $\left(C_{M, t}\right)$. 
The results from estimation of (14) are displayed in Table 4. Periods of negative returns to the market only significantly affect $\hat{\beta}_{S, t}$ for the health sector, leading to a fall in the value of the measure of undiversifiable risk. However, large negative innovations to the market portfolio uniformly lead to a significant increase in $\hat{\beta}_{S, t}$ across all sectors considered. There is no pattern of correlation between a negative return to the sector and changes in $\hat{\beta}_{S, t}$ with the sign and significance of $\phi_{5}$ being apparently random across sectors. Similarly, $C_{S, t}$ and $C_{M, t}$ do not appear to significantly affect estimates of systematic risk.

On the basis of the static estimates of $\beta_{S}$, the healthcare sector appears least risky. Using the mean of $\hat{\beta}_{S, t}$ as a measure of the relative riskiness of the sectors also suggests that the Healthcare sector is the least risky. However such a ranking clearly ignores relative uncertainty about the estimates of $\hat{\beta}_{S, t}$.

Figure 8 displays the empirical cumulative density functions (CDF) for the six estimated $\hat{\beta}_{S, t}$ series. Following González-Rivera (1996), we compare the market risk of the six sectors using the concepts of stochastic dominance. Here the least risky sector will dominate. Let $F_{X}(\beta)$ and $G_{Y}(\beta)$ be the CDF of $\beta$ for sectors $X$ and $Y$, respectively. If $F_{X}(\beta) \geq G_{Y}(\beta)$ for all $\beta$ then $X$ dominates $Y$ in the first order sense. The CDFs are constructed from the $1,10,25,50,75,90,95$ and 99 percentiles. In this context, there is no first order dominance as the CDFs all cut each other. That is, there is no clear least risky sector on the first order basis. Second order dominance requires that $\int_{-\infty}^{\beta}\left(F_{X}(\beta)-G_{Y}(\beta)\right) d \beta \geq 0$ for all $\beta$. In this context there are 15 possible pairs of series, so graphical representation is not useful. Using second order dominance, no clear ordering is obtained. It is therefore not possible to identify a clearly least risky sector using a pair wise approach. Further investigation of this issue is beyond the scope of the current paper. 


\section{Summary and Conclusions}

Recent research provides conflicting evidence as to whether abnormalities in equity returns are a result of changes in expected returns in an efficient market or an over-reaction to new information in a market that is inefficient. De Bondt and Thaler (1985), Chopra, Lakonishok and Ritter (1992), and Jegadeesh and Titman (1993) inter alia, conclude that the return to a portfolio formed by buying stocks which have suffered capital losses (losers) in the past, and selling stocks which have experienced capital gains (winners) in the past, has a higher average return that predicted by the CAPM. All three studies conclude that such overreaction is inconsistent with efficiency, since such contrarian strategies should not consistently earn excess returns.

On the other hand, Chan (1988), and Ball and Kothari (1989) argue that the time variation in expected return due to time-variation in beta explains the success of the 'losers' portfolio. The studies find that there exists predictive asymmetry in the response of the conditional beta to large positive and negative innovations. Braun, Nelson and Sunier (1995) find weak evidence of asymmetry in beta, but conclude that it is not sufficient to explain the over-reaction to information, or mean reversion in stock prices. Engle and Cho (1999) argue that this lack of evidence of asymmetry in beta is due to stock price aggregation, and lack of cross-sectional variation in the monthly data used by Braun, Nelson and Sunier (1995). Engle and Cho (1999) suggest that the use of daily data on individual stocks makes the detection of asymmetry an easier task.

This paper employs weekly data on industry sectors from the UK equity market to examine the impact of news on time-varying measures of beta. The use of weekly data on sectors of the market should overcome the potential price aggregation problems associated with lower frequency data, and maintain sufficient cross-sectional variation to detect time variation and asymmetry in beta.

Treating logarithmic price innovations as a collective measure of news arriving to the market between time $t-1$ and time $t$, the results suggest that time-variation in beta depends 
on two sources of news - news about the market and news about the sector. However, the asymmetric response of beta to news appears related only to large negative innovations to the market. Bad news about each individual sector does not appear to significantly affect the measure of undiversifiable risk. The asymmetric effect in beta is consistent across all sectors considered.

Given the magnitude of the asymmetry identified in beta, the evidence in this paper suggests that abnormalities such as mean reversion in stock prices may occur as a result of changes in expected return caused by time-variation and asymmetry in beta, rather than as a by-product of market inefficiency.

There is some evidence that the healthcare industry is the least risky of the sectors considered. However this evidence is at best indicative and does not take into account the higher moments of the empirical distribution of the estimated measures of market risk. Taking uncertainty about $\hat{\beta}_{S, t}$ into account it is not possible to order the sectors in terms of exposure to market risk. Further research on this subject is clearly a matter of interest. 


\section{References}

Akaike, H., (1974) "New look at statistical model identification", I.E.E.E Transactions on Automatic Control, AC-19, 716-723.

Attanasio, O.P. (1991) "Risk, time varying second moments and market efficiency", Review of Economic Studies, 58, 479-494.

Baillie, R.T. and Myers, R.J. (1991) "Bivariate GARCH Estimation of the Optimal Commodity Futures Hedge" Journal of Applied Econometrics, 6, 109-124.

Ball, R., and Kothari, S.P. (1989) "Non-stationary expected returns: Implications for tests of market efficiency and serial correlation in returns", Journal of Financial Economics, 25, 5174.

Black, F. (1976) "Studies in price volatility changes", Proceedings of the 1976 Meeting of the Business and Economics Statistics Section, American Statistical Association, 177-181.

Bollerslev, T., Engle, R.F. and Wooldridge, J.M. (1988) "A capital asset pricing model with time-varying covariances”, Journal of Political Economy, 96, 116-31.

Braun, P.A., Nelson, D.B., and Sunier, A.M. (1995) "Good News, Bad News, Volatility and Betas", Journal of Finance, 50, 1575-1603.

Brooks C. and Henry, Ó. T. (2000), "Linear and Non-Linear Transmission of Equity Return Volatility: Evidence from the US, Japan and Australia”, Economic Modelling, 17, 497-513.

Brooks, C., Henry Ó.T. and Persand, G. (2002) "The Effect of Asymmetries on Optimal Hedge Ratios" Journal of Business 75(2), 333-352.

Campbell, J. and Hentschel, L. (1992) "No news is good news: An asymmetric model of changing volatility in stock returns", Journal of Financial Economics, 31, 281-318.

Christie, A. (1982) "The stochastic behaviour of common stock variance: Value, leverage and interest rate effects", Journal of Financial Economics, 10, 407-432.

Chopra, N., Lakonishok, J., and Ritter, J. (1992) "Measuring abnormal returns: Do stocks overreact?" Journal of Financial Economics, 10, 289-321.

DeBondt, W., and Thaler, R., (1985) "Does the stock market overreact?" The Journal of Finance, 40, 793-805

Engel, C., Frankel, J.A., Froot, K.A., and Rodrigues, A.P. (1995) "Tests of Conditional Mean-Variance Efficiency of the U.S. Stock Market”, Journal of Empirical Finance, 2, 3-18.

Engle, R.F. (1982) "Autoregressive conditional heteroscedasticity with estimates of the variance of United Kingdom inflation”, Econometrica, 50, 987-1007.

Engle, R.F., and Cho, Y-H, (1999) "Time Varying Betas and Asymmetric Effects of News: Empirical Analysis of Blue Chip Stocks", NBER Working Paper No 7330

Engle, R.F and Kroner, K. (1995) "Multivariate simultaneous generalized ARCH", Econometric Theory, 11, 122-150. 
Engle, R.F. and Ng, V. (1993) "Measuring and testing the impact of news on volatility", Journal of Finance, 48, 1749-1778.

Glosten, L.R., Jagannathan, R. and Runkle, D. (1993) "On the relation between the expected value and the volatility of the nominal excess return on stocks", Journal of Finance, 48, 1779-1801.

González-Rivera, G. (1996) "Time varying risk: The case of the American computer industry”, Journal of Empirical Finance, 2, 333-342.

Hansen L.P. and Singleton, K. (1983) "Stochastic consumption, risk aversion, and the temporal behaviour of asset returns", Journal of Political Economy, 91, 249-266.

Henry, Ó.T. (1998) "Modelling the Asymmetry of Stock Market Volatility", Applied Financial Economics, 8, 145 - 153.

Henry, Ó.T. and Sharma J.S. (1999) "Asymmetric Conditional Volatility and Firm Size: Evidence from Australian Equity Portfolios", Australian Economic Papers, 38, 393 - 407

Jegadeesh, N., and Titman, S., (1993) "Returns to buying winners and selling losers: Implications for stock market efficiency", Journal of Finance, 48, 65-91.

Kroner, K.F. and Sultan, J. (1991) "Exchange Rate Volatility and Time Varying Hedge Ratios" in Rhee, S.G. and Chang, R.P. (eds.) Pacific Basin Capital Markets Research Elsevier, North Holland

Kroner, K.F., and Ng, V.K. (1996) "Multivariate GARCH Modelling of Asset Returns", Papers and Proceedings of the American Statistical Association, Business and Economics Section, 31-46.

Merton, R.C. (1973) “An Intertemporal Asset Pricing Model”, Econometrica, 41, 867-887.

Merton, R.C. (1980) "On Estimating the Expected Return on the Market: An Exploratory Investigation", Journal of Financial Economics, 8, 323-361.

Pagan, A.R., and Schwert, G.W. (1990) "Alternative Models for Conditional Stock Volatility", Journal of Econometrics, 45, 267-290

Schwarz, G. (1978) "Estimating the dimensions of a model”, Annals of Statistics, 6, 461-464. 
Tables and Figures

\begin{tabular}{lllllllll}
\hline \hline \multirow{2}{*}{ Series } & \multirow{2}{*}{ Mean } & Variance & Skew & E.K. & $\rho_{1}$ & Q(5) & $Q^{2}(5)$ & $\beta$ \\
\hline \hline FTALL & 0.280 & 6.288 & -0.323 & 9.082 & 0.071 & 56.67 & 231.036 & 1.00 \\
& & & {$[0.000]$} & {$[0.000]$} & & {$[0.000]$} & {$[0.000]$} & \\
BASIC & \multirow{2}{*}{0.226} & \multirow{2}{*}{7.690} & -0.517 & 7.975 & 0.079 & 44.447 & 55.825 & 0.976 \\
& & & {$[0.000]$} & {$[0.000]$} & & {$[0.000]$} & {$[0.000]$} & $(0.012)$ \\
TOTLF & \multirow{2}{*}{0.303} & \multirow{2}{*}{7.260} & 0.007 & 6.941 & 0.111 & 56.668 & 342.389 & 0.978 \\
& & & {$[0.900]$} & {$[0.000]$} & & {$[0.000]$} & {$[0.000]$} & $(0.010)$ \\
HLTH & 0.280 & \multirow{2}{*}{10.842} & -0.061 & 5.459 & 0.016 & 21.715 & 155.245 & 0.930 \\
& & & {$[0.290]$} & {$[0.000]$} & & {$[0.001]$} & {$[0.000]$} & $(0.022)$ \\
PUBLS & 0.245 & \multirow{2}{*}{9.883} & -0.650 & 10.531 & 0.107 & 48.013 & 107.912 & 1.040 \\
& & & {$[0.000]$} & {$[0.000]$} & & {$[0.000]$} & {$[0.000]$} & $(0.016)$ \\
RTAIL & 0.256 & \multirow{2}{*}{11.129} & 0.168 & 3.737 & 0.002 & 6.009 & 122.797 & 1.079 \\
& & & {$[0.000]$} & {$[0.000]$} & & {$[0.305]$} & {$[0.000]$} & $(0.018)$ \\
RLEST & 0.249 & \multirow{2}{*}{11.908} & -0.159 & 6.579 & 0.097 & 33.713 & 391.338 & 1.032 \\
& & & {$[0.000]$} & {$[0.000]$} & & {$[0.000]$} & {$[0.000]$} & $(0.021)$ \\
\hline \hline
\end{tabular}

Notes to Table 1: Marginal significance levels displayed as [.], standard errors displayed as (.). Skew measures the standardised third moment of the distribution and reports the marginal significance of a test for zero skewness. E.K. reports the excess kurtosis of the return distribution and the associated marginal significance level for the test of zero excess kurtosis. The first order autocorrelation coefficient is $\rho_{1}$. Q(5) and $\mathrm{Q}^{2}(5)$ are Ljung-Box tests for fifth order serial correlation in the returns and the squared returns, respectively. Both tests are distributed as $\chi^{2}(5)$ under the null. $\beta$ is the OLS estimate of the measure of undiversifiable risk. 


\begin{tabular}{|c|c|c|c|c|c|c|}
\hline \multicolumn{7}{|c|}{ Table 2a: Conditional Mean Estimates } \\
\hline & BASIC & TOTLF & HLTH & PUBLS & RTAIL & RLEST \\
\hline \multirow[t]{2}{*}{$\mu^{(M)}$} & 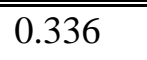 & 0.288 & $\bar{~} 0.157$ & 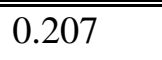 & $\overline{c 0.099}$ & "0.258 \\
\hline & $(0.043)$ & $(0.053)$ & $(0.041)$ & $(0.0350)$ & $(0.034)$ & $(0.038)$ \\
\hline \multirow{2}{*}{$\Gamma_{1, M}^{(M)}$} & -0.171 & -0.033 & 0.199 & -0.086 & 0.171 & -0.103 \\
\hline & $(0.017)$ & $(0.011)$ & $(0.028)$ & $(0.018)$ & $(0.012)$ & $(0.019)$ \\
\hline \multirow{2}{*}{$\Gamma_{2, M}^{(M)}$} & 0.130 & 0.055 & 0.038 & 0.114 & 0.145 & 0.087 \\
\hline & $(0.011)$ & $(0.010)$ & $(0.015)$ & $(0.015)$ & $(0.012)$ & $(0.013)$ \\
\hline \multirow{2}{*}{$\Gamma_{1, S}^{(M)}$} & 0.051 & 0.042 & 0.002 & 0.047 & 0.036 & 0.018 \\
\hline & $(0.009)$ & $(0.011)$ & $(0.012)$ & $(0.021)$ & $(0.009)$ & $(0.011)$ \\
\hline \multirow{2}{*}{$\Gamma_{2, S}^{(M)}$} & -0.003 & 0.062 & 0.062 & 0.005 & -0.024 & 0.026 \\
\hline & $(0.011)$ & $(0.008)$ & $(0.011)$ & $(0.011)$ & $(0.009)$ & $(0.010)$ \\
\hline \multirow{2}{*}{$\Theta_{1, M}^{(M)}$} & 0.153 & 0.008 & -0.019 & 0.061 & -0.202 & 0.117 \\
\hline & $(0.016)$ & $(0.012)$ & $(0.024)$ & $(0.021)$ & $(0.012)$ & $(0.020)$ \\
\hline \multirow{2}{*}{$\mu^{(S)}$} & 0.150 & 0.363 & 0.134 & 0.242 & 0.222 & 0.160 \\
\hline & $(0.013)$ & $(0.068)$ & $(0.068)$ & $(0.038)$ & $(0.057)$ & $(0.045)$ \\
\hline \multirow[t]{2}{*}{$\Gamma_{1, M}^{(S)}$} & -0.023 & 0.005 & 0.117 & 0.053 & -0.021 & 0.003 \\
\hline & $(0.013)$ & $(0.012)$ & $(0.021)$ & $(0.030)$ & $(0.021)$ & $(0.018)$ \\
\hline \multirow[t]{2}{*}{$\Gamma_{2, M}^{(S)}$} & 0.113 & 0.032 & 0.090 & 0.216 & 0.156 & 0.040 \\
\hline & $(0.018)$ & $(0.011)$ & $(0.020)$ & $(0.017)$ & $(0.020)$ & $(0.018)$ \\
\hline \multirow[t]{2}{*}{$\Gamma_{1, S}^{(S)}$} & 0.147 & -0.011 & -0.097 & 0.056 & -0.057 & 0.094 \\
\hline & $(0.019)$ & $(0.010)$ & $(0.015)$ & $(0.016)$ & $(0.013)$ & $(0.012)$ \\
\hline \multirow{2}{*}{$\Gamma_{2, S}^{(S)}$} & 0.002 & 0.080 & 0.008 & -0.048 & -0.071 & 0.009 \\
\hline & $(0.012)$ & $(0.010)$ & $(0.015)$ & $(0.013)$ & $(0.013)$ & $(0.012)$ \\
\hline \multirow[t]{2}{*}{$\Theta_{1, S}^{(S)}$} & -0.089 & 0.062 & 0.053 & -0.016 & 0.031 & -0.003 \\
\hline & $(0.021)$ & $(0.011)$ & $(0.014)$ & $(0.021)$ & $(0.013)$ & $(0.013)$ \\
\hline
\end{tabular}

Notes to Table 2a: Standard errors displayed as (.) 


\begin{tabular}{|c|c|c|c|c|c|c|}
\hline \multicolumn{7}{|c|}{ Table 2b: Conditional Variance Estimates } \\
\hline & BASIC & TOTLF & HLTH & PUBLS & RTAIL & RLEST \\
\hline \multirow[t]{2}{*}{$\overline{c_{11}}$} & "0.404 & "0.167 & $=0.479$ & 0.610 & 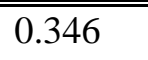 & " 0.506 \\
\hline & $(0.060)$ & $(0.055)$ & $(0.062)$ & $(0.060)$ & $(0.034)$ & $(0.080)$ \\
\hline \multirow[t]{2}{*}{$c_{12}$} & 0.399 & 0.298 & 0.118 & -0.140 & 0.154 & 0.396 \\
\hline & $(0.069)$ & $(0.052)$ & $(0.070)$ & $(0.124)$ & $(0.048)$ & $(0.048)$ \\
\hline \multirow[t]{2}{*}{$\mathrm{c}_{22}$} & 0.180 & 0.127 & 0.409 & 0.261 & 0.082 & 0.261 \\
\hline & $(0.030)$ & $(0.038)$ & $(0.111)$ & $(0.144)$ & $(0.054)$ & $(0.051)$ \\
\hline \multirow[t]{2}{*}{$a_{11}$} & 0.948 & 0.986 & 0.902 & 0.707 & 0.907 & 0.915 \\
\hline & $(0.016)$ & $(0.011)$ & $(0.022)$ & $(0.042)$ & $(0.011)$ & $(0.027)$ \\
\hline \multirow[t]{2}{*}{$a_{12}$} & -0.009 & 0.013 & -0.053 & -0.115 & -0.064 & -0.065 \\
\hline & $(0.021)$ & $(0.013)$ & $(0.033)$ & $(0.048)$ & $(0.015)$ & $(0.027)$ \\
\hline \multirow[t]{2}{*}{$a_{21}$} & -0.008 & -0.025 & 0.032 & 0.201 & 0.036 & 0.015 \\
\hline & $(0.011)$ & $(0.011)$ & $(0.016)$ & $(0.034)$ & $(0.006)$ & $(0.017)$ \\
\hline \multirow[t]{2}{*}{$a_{22}$} & 0.954 & 0.940 & 0.972 & 1.026 & 1.016 & 0.973 \\
\hline & $(0.016)$ & $(0.013)$ & $(0.022)$ & $(0.039)$ & $(0.008)$ & $(0.016)$ \\
\hline \multirow[t]{2}{*}{$b_{11}$} & 0.218 & 0.286 & 0.146 & -0.027 & 0.237 & 0.238 \\
\hline & $(0.050)$ & $(0.042)$ & $(0.043)$ & $(0.055)$ & $(0.041)$ & $(0.041)$ \\
\hline \multirow[t]{2}{*}{$b_{12}$} & -0.283 & 0.152 & 0.103 & 0.308 & 0.085 & 0.099 \\
\hline & $(0.059)$ & $(0.047)$ & $(0.054)$ & $(0.068)$ & $(0.054)$ & $(0.048)$ \\
\hline \multirow[t]{2}{*}{$b_{21}$} & 0.013 & -0.071 & 0.015 & 0.094 & -0.027 & -0.044 \\
\hline & $(0.046)$ & $(0.038)$ & $(0.029)$ & $(0.039)$ & $(0.027)$ & $(0.030)$ \\
\hline \multirow[t]{2}{*}{$b_{22}$} & 0.212 & 0.094 & 0.207 & -0.046 & 0.080 & 0.178 \\
\hline & $(0.052)$ & $(0.049)$ & $(0.049)$ & $(0.051)$ & $(0.035)$ & $(0.034)$ \\
\hline \multirow[t]{2}{*}{$\mathrm{d}_{11}$} & 0.356 & -0.085 & 0.398 & 0.456 & 0.465 & 0.057 \\
\hline & $(0.087)$ & $(0.081)$ & $(0.065)$ & $(0.072)$ & $(0.059)$ & $(0.095)$ \\
\hline \multirow[t]{2}{*}{$d_{12}$} & 0.359 & -0.226 & 0.326 & 0.215 & 0.353 & -0.075 \\
\hline & $(0.092)$ & $(0.085)$ & $(0.104)$ & $(0.089)$ & $(0.063)$ & $(0.109)$ \\
\hline \multirow[t]{2}{*}{$\mathrm{d}_{21}$} & -0.059 & 0.264 & -0.054 & 0.063 & -0.236 & 0.192 \\
\hline & $(0.096)$ & $(0.061)$ & $(0.059)$ & $(0.061)$ & $(0.038)$ & $(0.055)$ \\
\hline \multirow[t]{2}{*}{$d_{22}$} & -0.051 & 0.418 & -0.075 & 0.110 & -0.082 & 0.324 \\
\hline & $(0.104)$ & $(0.073)$ & $(0.102)$ & $(0.071)$ & $(0.049)$ & $(0.071)$ \\
\hline
\end{tabular}

Notes to Table 2b: Standard errors displayed as (.) 


\begin{tabular}{|c|c|c|c|c|c|c|}
\hline \multicolumn{7}{|c|}{ Table 2c: GARCH-M Coefficient Estimates and Residual Diagnostics } \\
\hline & BASIC & TOTLF & HLTH & PUBLS & RTAIL & RLEST \\
\hline \multirow[t]{2}{*}{$\psi_{1, S}$} & -0.004 & 0.030 & -0.023 & -0.084 & -0.028 & 0.011 \\
\hline & $(0.004)$ & $(0.006)$ & $(0.009)$ & $(0.025)$ & $(0.009)$ & $(0.007)$ \\
\hline \multirow[t]{2}{*}{$\psi_{1, S M}$} & 0.013 & -0.020 & 0.005 & 0.011 & -0.023 & -0.008 \\
\hline & $(0.004)$ & $(0.012)$ & $(0.008)$ & $(0.005)$ & $(0.006)$ & $(0.005)$ \\
\hline \multirow[t]{2}{*}{$\psi_{1, M}$} & -0.011 & -0.011 & 0.0180 & 0.057 & 0.040 & 0.009 \\
\hline & $(0.006)$ & $(0.008)$ & $(0.003)$ & $(0.018)$ & $(0.004)$ & $(0.003)$ \\
\hline \multirow{2}{*}{$\psi_{2, S}$} & 0.022 & -0.033 & 0.003 & 0.020 & -0.005 & -0.028 \\
\hline & $(0.004)$ & $(0.012)$ & $(0.012)$ & $(0.011)$ & $(0.013)$ & $(0.008)$ \\
\hline \multirow{2}{*}{$\psi_{2, S M}$} & -0.008 & 0.012 & 0.003 & 0.017 & 0.062 & 0.055 \\
\hline & $(0.005)$ & $(0.005)$ & $(0.010)$ & $(0.010)$ & $(0.007)$ & $(0.007)$ \\
\hline \multirow[t]{2}{*}{$\psi_{2, M}$} & -0.007 & 0.010 & 0.012 & -0.028 & 0.032 & -0.005 \\
\hline & $(0.004)$ & $(0.006)$ & $(0.006)$ & $(0.013)$ & $(0.007)$ & $(0.005)$ \\
\hline \multirow[t]{2}{*}{$\eta$} & 9.254 & 9.162 & 8.086 & 8.345 & 8.514 & 8.751 \\
\hline & $(0.554)$ & $(0.583)$ & $(0.4282)$ & $(0.626)$ & $(0.573)$ & $(0.227)$ \\
\hline $\log \mathrm{L}$ & -4747.75 & -4536.92 & -5887.25 & -5396.13 & -5580.52 & -5718.42 \\
\hline \multirow[t]{2}{*}{$\mathrm{Q}(5)^{\mathrm{M}}$} & 10.365 & 11.961 & 13.832 & 10.423 & 12.070 & 10.417 \\
\hline & {$[0.066]$} & {$[0.035]$} & [0.017] & [0.064] & {$[0.034]$} & {$[0.064]$} \\
\hline \multirow[t]{2}{*}{$\mathrm{Q}^{2}(5)^{\mathrm{M}}$} & 0.904 & 0.846 & 1.140 & 1.209 & 1.740 & 0.492 \\
\hline & {$[0.970]$} & [0.974] & [0.951] & [0.944] & {$[0.884]$} & [0.992] \\
\hline \multirow[t]{2}{*}{$\mathrm{Q}(5)^{\mathrm{S}}$} & 7.370 & 10.241 & 9.491 & 3.310 & 2.956 & 7.459 \\
\hline & [0.195] & [0.069] & [0.091] & {$[0.652]$} & [0.707] & [0.189] \\
\hline \multirow[t]{2}{*}{$Q^{2}(5)^{S}$} & 0.935 & 2.754 & 10.584 & 1.042 & 4.916 & 10.267 \\
\hline & [0.967] & {$[0.738]$} & {$[0.060]$} & [0.959] & {$[0.426]$} & {$[0.068]$} \\
\hline
\end{tabular}

Notes to Table 2c: Standard errors displayed as (.). Marginal significance levels displayed as [.]. $\eta$ represents the degrees of freedom parameter estimated from the students- $t$ density. $Q(5)^{i}$ and $Q^{2}(5)^{i}$ represent Ljung Box tests for serial dependence in the standardised residuals and their corresponding squares for $i=$ Market, Sector 


\begin{tabular}{lllllll}
\hline \hline \multicolumn{7}{c}{ Table 3: Descriptive Statistics for $\hat{\beta}_{S, t}$} \\
& BASIC & TOTLF & HLTH & PUBLS & RTAIL & RLEST \\
\hline \hline Mean & 0.988 & 0.965 & 0.881 & 0.972 & 1.108 & 0.906 \\
Variance & 0.010 & 0.015 & 0.029 & 0.008 & 0.023 & 0.037 \\
Skew & -0.081 & 0.446 & 1.210 & 0.1704 & -0.207 & 0.375 \\
& {$[0.000]$} & {$[0.000]$} & {$[0.000]$} & {$[0.003]$} & {$[0.000]$} & {$[0.000]$} \\
\multirow{2}{*}{ E.K. } & 2.516 & -0.120 & 4.571 & 1.561 & -0.394 & -0.185 \\
& {$[0.000]$} & {$[0.297]$} & {$[0.000]$} & {$[0.000]$} & {$[0.001]$} & {$[0.109]$} \\
Min & 0.516 & 0.642 & 0.527 & 0.564 & 0.630 & 0.440 \\
Max & 1.320 & 1.322 & 1.924 & 1.512 & 1.480 & 1.484 \\
ADF & -5.045 & -4.759 & -6.506 & -7.828 & -5.377 & -6.366 \\
\hline \hline
\end{tabular}

Notes to Table 3: Marginal significance levels displayed as [.]. Skew measures the standardised third moment of the distribution and reports the marginal significance of a test for zero skewness. E.K. reports the excess kurtosis of the distribution and the associated marginal significance level for the test of zero excess kurtosis. ADF is an Augmented Dickey-Fuller (1981) test for a unit root in $\hat{\beta}_{S, t}$, the $5 \%$ critical value for the ADF test is -2.8636 . 


\begin{tabular}{lllllll}
\hline \hline \multicolumn{7}{c}{ Table 4: Sources of Asymmetry in $\hat{\beta}_{S, t}$} \\
\\
\hline \hline$\phi_{1}$ & BASIC & TOTLF & HLTH & PUBLS & RTAIL & RLEST \\
& $0.993^{*}$ & $0.959^{*}$ & $0.900^{*}$ & $0.983^{*}$ & $1.237^{*}$ & $0.909^{*}$ \\
$\phi_{2}$ & $(0.003)$ & $(0.004)$ & $(0.006)$ & $(0.003)$ & $(0.005)$ & $(0.006)$ \\
& 0.008 & 0.004 & $-0.040^{*}$ & -0.007 & 0.002 & -0.011 \\
$\phi_{3}$ & $(0.007)$ & $(0.009)$ & $(0.011)$ & $(0.006)$ & $(0.010)$ & $(0.012)$ \\
& $0.056^{*}$ & $0.052^{*}$ & $0.019^{*}$ & $0.040^{*}$ & $0.051^{*}$ & $0.027^{*}$ \\
$\phi_{4}$ & $(0.007)$ & $(0.012)$ & $(0.008)$ & $(0.005)$ & $(0.009)$ & $(0.009)$ \\
& -0.001 & -0.009 & $-0.039^{*}$ & $-0.015^{*}$ & -0.007 & $-0.065^{*}$ \\
$\phi_{5}$ & $(0.007)$ & $(0.009)$ & $(0.011)$ & $(0.006)$ & $(0.011)$ & $(0.011)$ \\
& $0.023^{*}$ & $-0.032^{*}$ & $-0.019 *$ & -0.001 & -0.009 & $-0.035^{*}$ \\
$\phi_{6}$ & $(0.007)$ & $(0.010)$ & $(0.005)$ & $(0.005)$ & $(0.006)$ & $(0.006)$ \\
& $-0.036^{*}$ & -0.012 & -0.014 & -0.022 & $-0.027^{*}$ & $-0.016^{*}$ \\
$\phi_{7}$ & $(0.006)$ & $(0.012)$ & $(0.008)$ & $(0.005)$ & $(0.009)$ & $(0.008)$ \\
& $-0.039^{*}$ & -0.017 & -0.004 & $-0.020^{*}$ & $-0.022^{*}$ & $-0.014^{*}$ \\
& $(0.007)$ & $(0.010)$ & $(0.005)$ & $(0.004)$ & $(0.006)$ & $(0.006)$ \\
\hline \hline & 135.120 & 141.991 & 88.279 & 173.451 & 78.217 & 285.049 \\
& {$[0.000]$} & {$[0.000]$} & {$[0.000]$} & {$[0.000]$} & {$[0.000]$} & {$[0.000]$} \\
\hline \hline
\end{tabular}

Notes to Table 4: Marginal significance levels displayed as [.]. Standard errors displayed as (.). * denotes significance at the $5 \%$ level. 

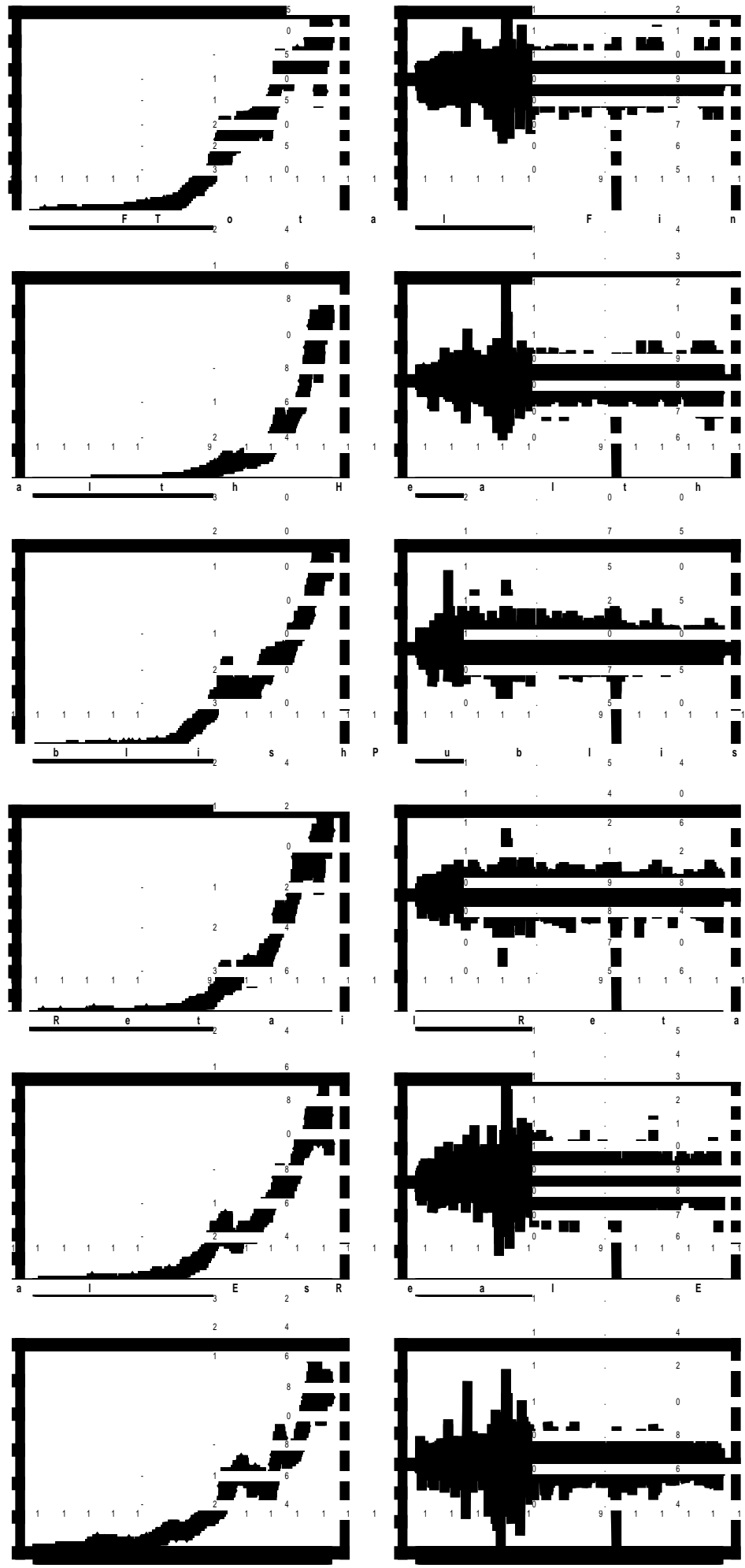
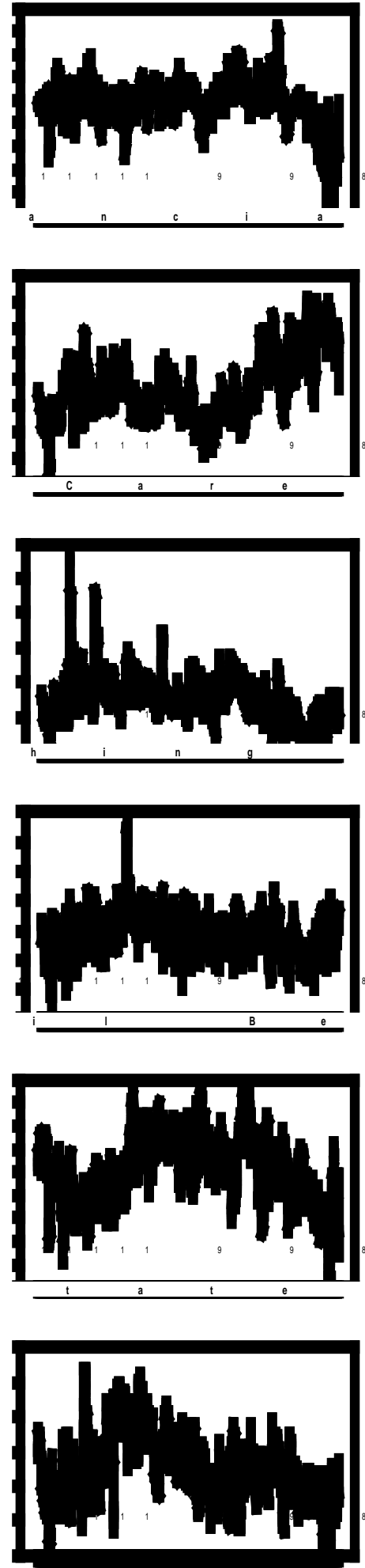

Figure 1: Sector index, sector return and estimated sector beta 

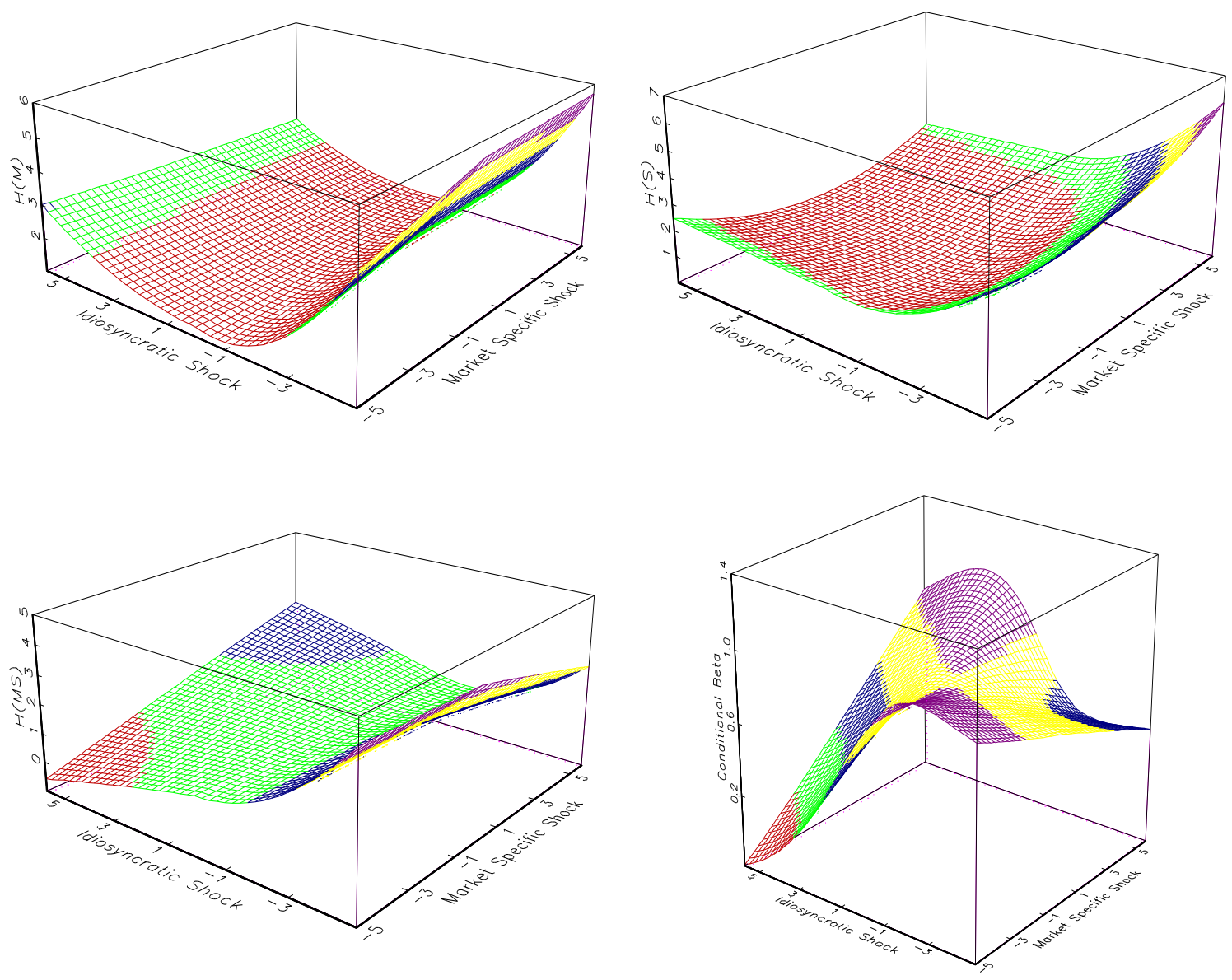

Figure 2: News Impact Surfaces for Basic Industries 

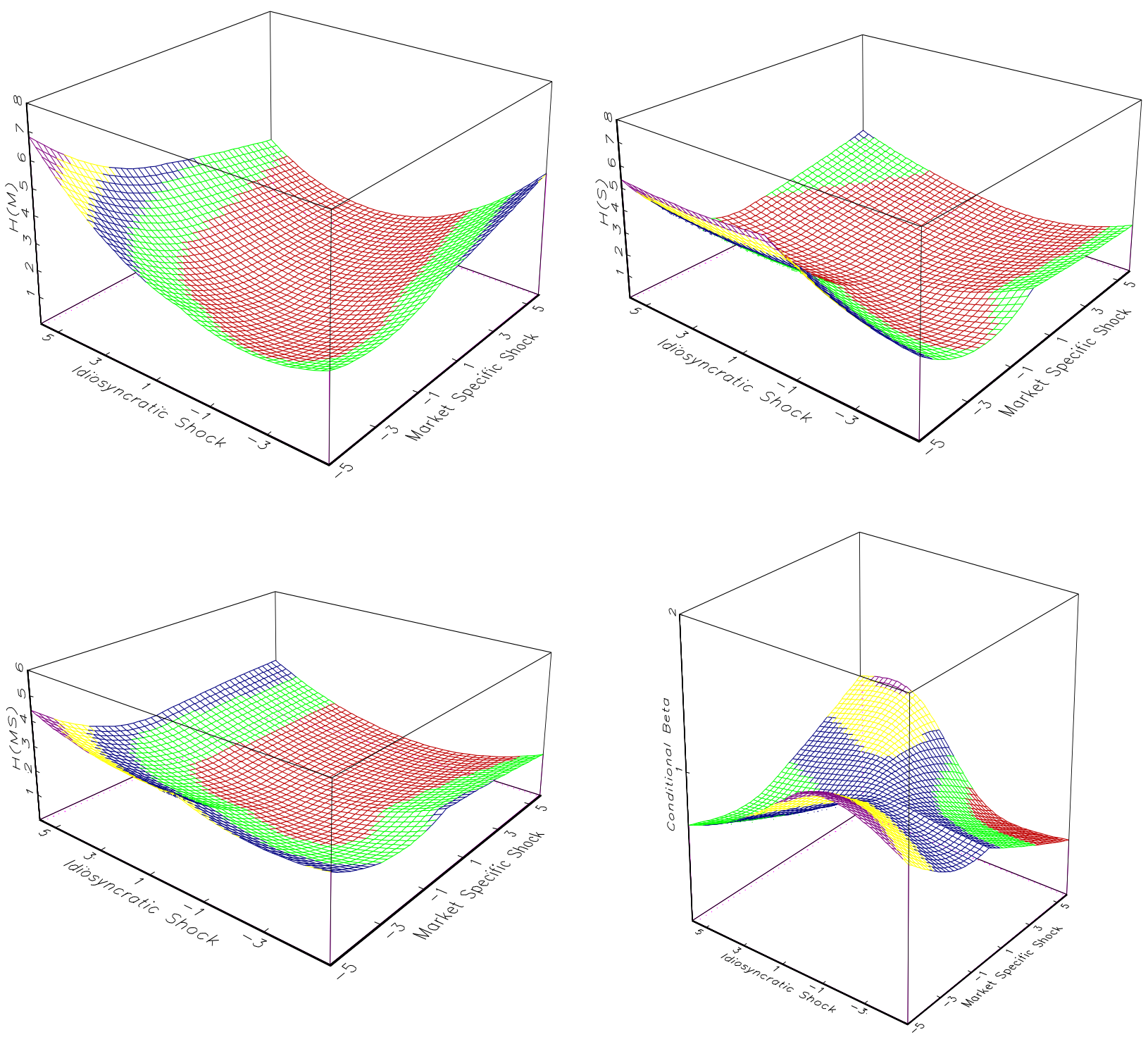

Figure 3: News Impact Surfaces for Total Financial 

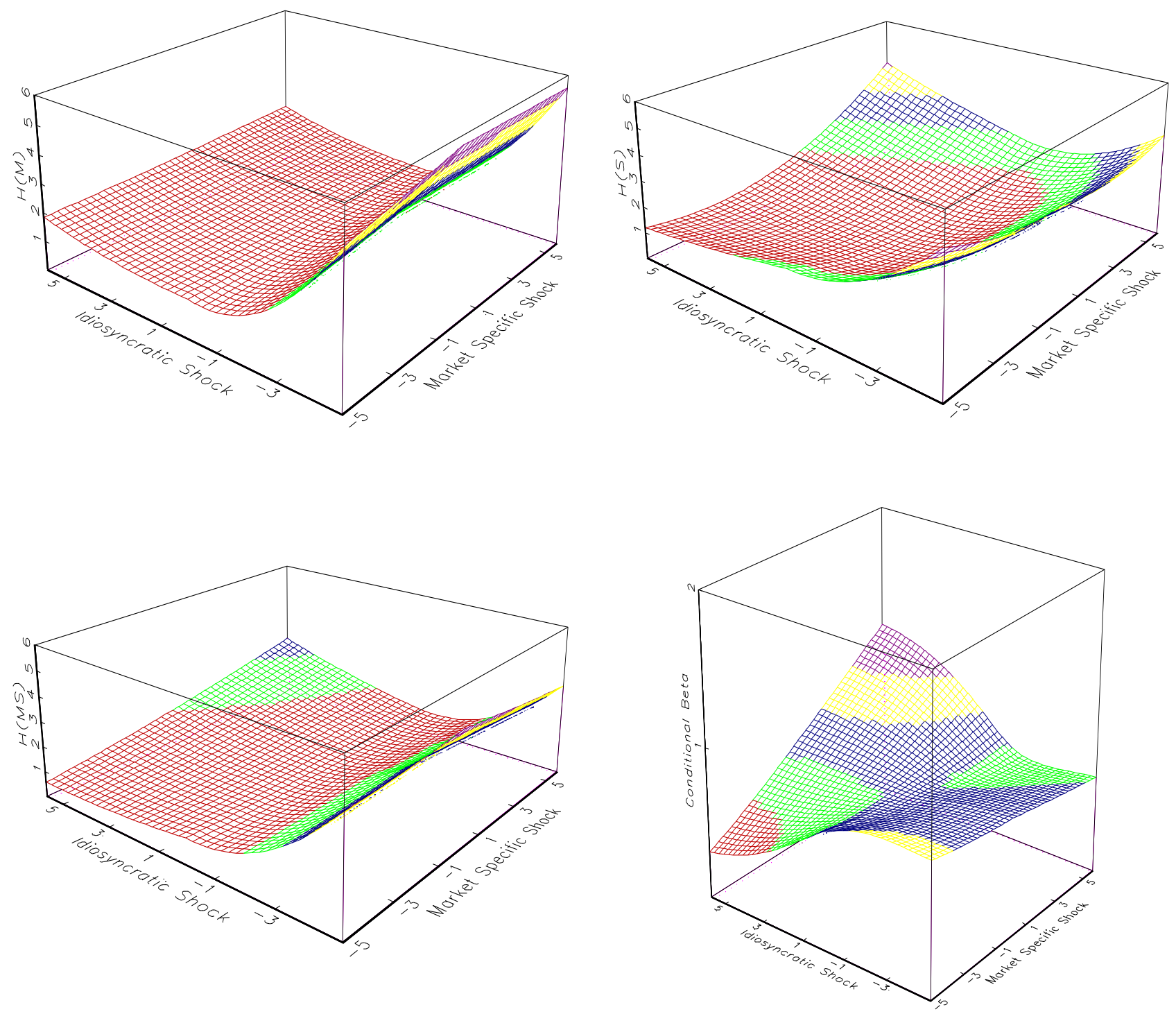

Figure 4: News Impact Surfaces for Healthcare 

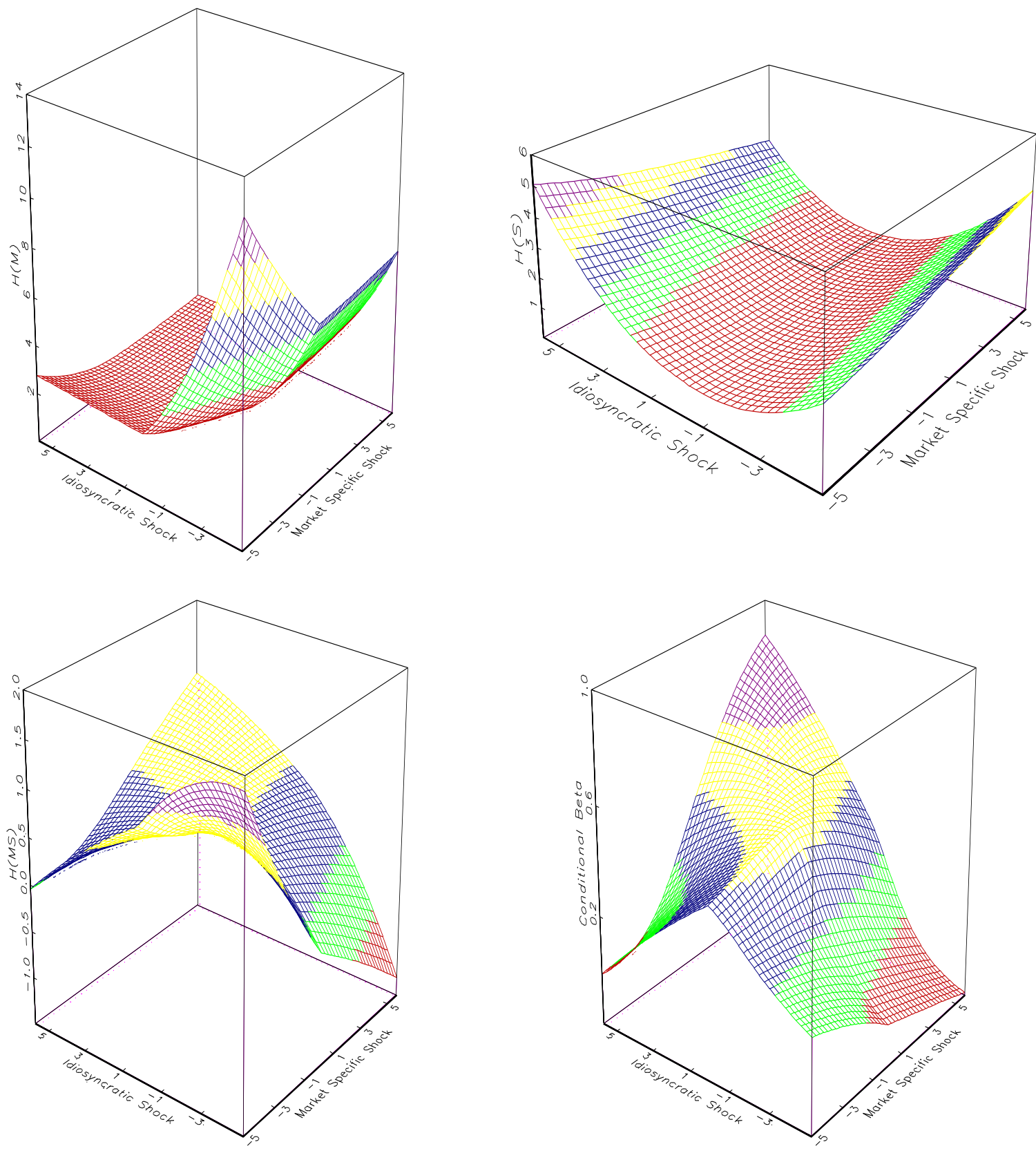

Figure 5: News Impact Surfaces for Publishing 

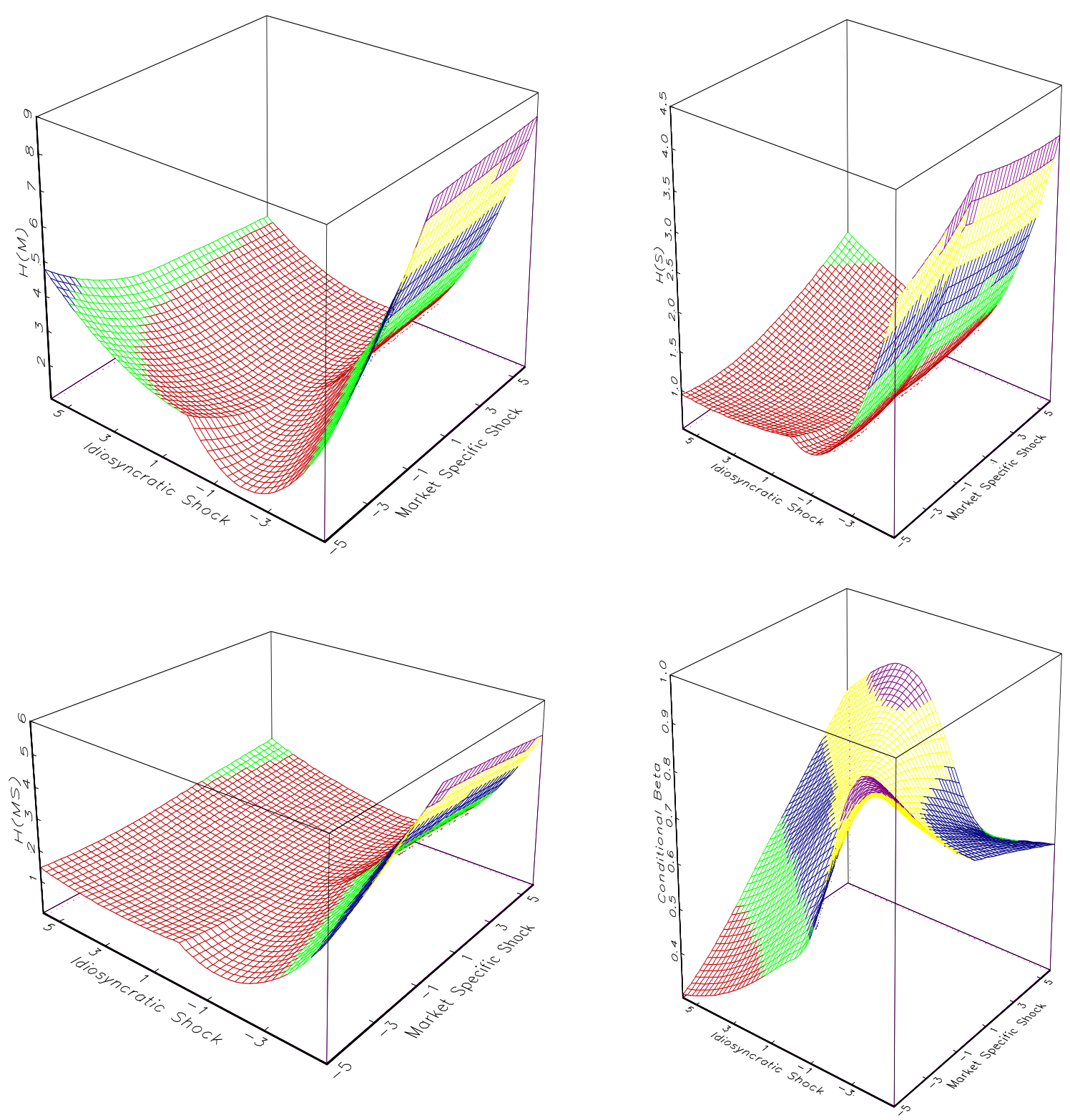

Figure 6: News Impact Surfaces for Retail 

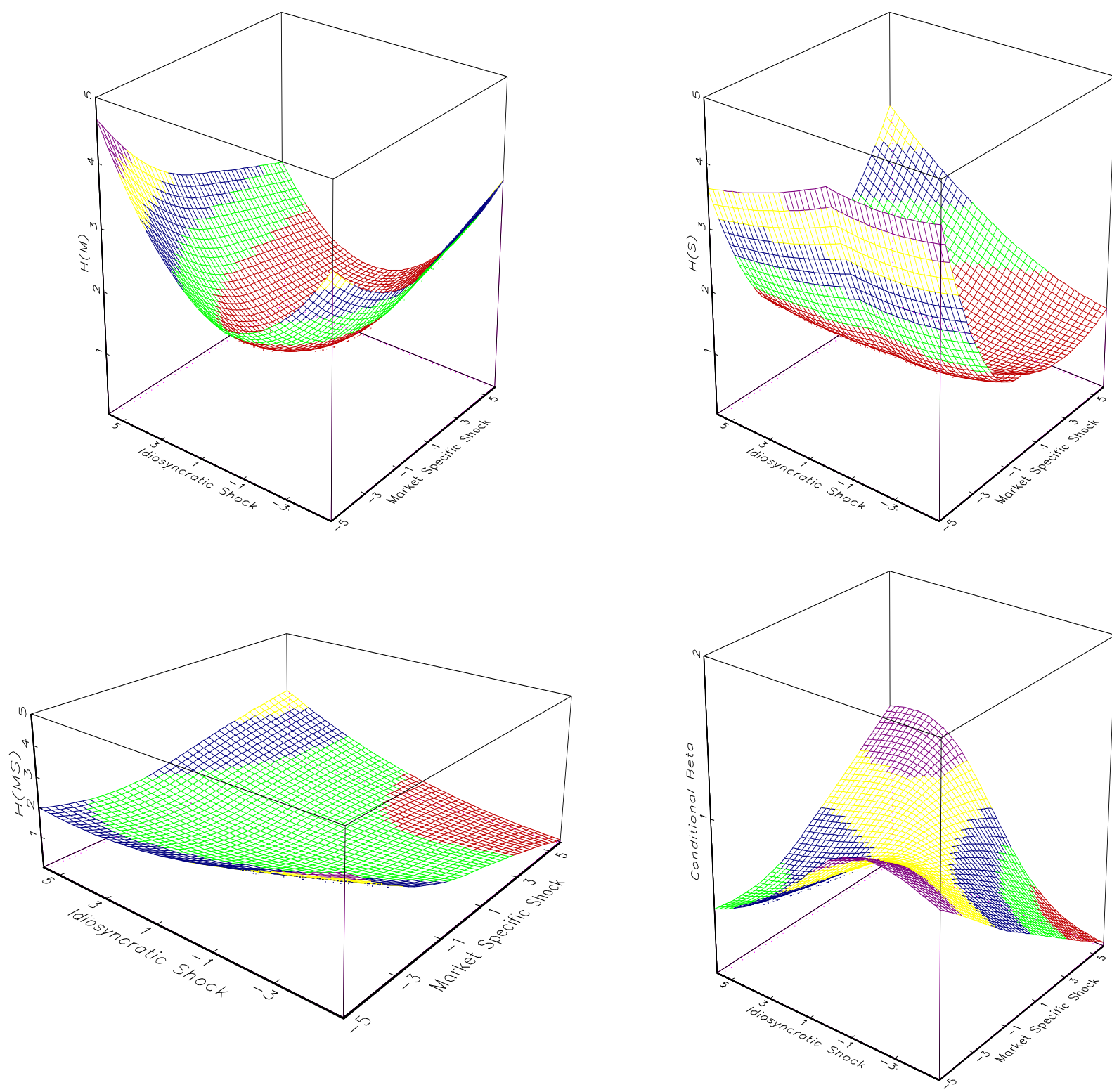

Figure 7: News Impact Surfaces for Real Estate 


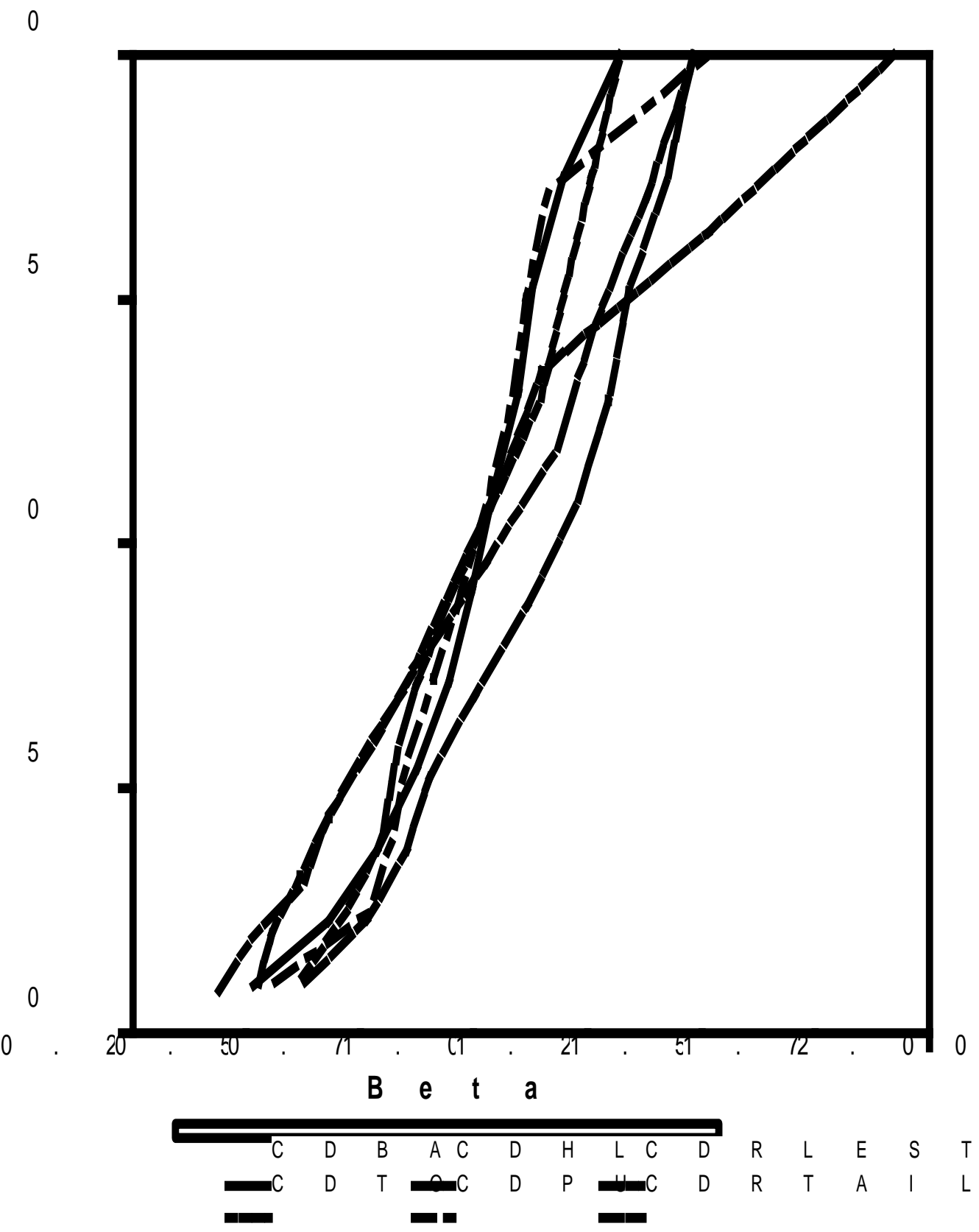

Figure 8: Cumulative distribution functions for the Sector $\hat{\beta}_{S, t}$ 